\title{
P125: Promoting hand hygiene in intensive care: a permanent challenge
}

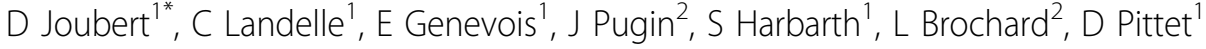 \\ From 2nd International Conference on Prevention and Infection Control (ICPIC 2013) \\ Geneva, Switzerland. 25-28 June 2013
}

\section{Introduction}

Healthcare workers (HCWs) compliance with hand hygiene $(\mathrm{HH})$ remains a permanent challenge in ICUs and requires repeated adaptation of practices.

\section{Objectives}

To monitor compliance with $\mathrm{HH}$ and appropriate use of gloves to help improving daily infection control practices.

\section{Methods}

We monitored $\mathrm{HH}$ according to the WHO "My Five Moments for Hand Hygiene" concept and reviewed the appropriate use of gloves in a 36-bed mixed adult ICU admitting 2500 patients per year for an average length of stay of 3 days. The attack rate of methicillin-resistant Staphylococcus aureus(MRSA) cross-transmission was monitored based on active surveillance screening. In 2012, 9 \% of admitted patients in the ICU carried MRSA. The intervention to improve $\mathrm{HH}$ practices included: simplifying the WHO "patient zone" concept in harmony with all wards at HUG; benchmarking of $\mathrm{HH}$ compliance with hospital-wide rates; promoting adherence with $\mathrm{HH}$, with emphasis on improving adherence with the indication "before aseptic care"; stopping the routine use of gloves for "contact isolation" (except for $C$. difficile). Strategy implementation also included: additional installation and improved localization of alcohol-based handrub dispensers; teaching of glove use for paramedical staff; simulator training; and targeted training of new staff and clinical leaders.

\section{Results}

A total of 1680 opportunities for $\mathrm{HH}$ were observed in 2011/2012. Overall compliance with HH improved from $51 \%$ in 2011 to $60 \%$ in 2012, and compliance with the WHO "before aseptic task" indication improved from $39 \%$ to $49 \%$, respectively. Improvement was significant for all major $\mathrm{HCW}$ categories: nurses (from 59\% to $65 \%$ ), doctors (from $45 \%$ to $59 \%$ ) and nursing assistants (from $41 \%$ to $66 \%$ ). The MRSA attack rate decreased in parallel from $4.9 \mathrm{ICU}$-acquired cases/1000 patient-days in 2011 to 2.4 in 2012 .

\section{Conclusion}

The significant decrease of MRSA transmission associated with improved adherence to $\mathrm{HH}$ is encouraging. The 2013 target is to achieve an overall compliance with $\mathrm{HH}$ of $70 \%$ in ICU. Efforts will focus on a multimodal innovative approach.

\section{Disclosure of interest}

None declared.

\section{Author details}

'Infection Control Program, University of Geneva Hospital, Geneva,

Switzerland. ${ }^{2}$ Intensive Care Unit, University of Geneva Hospital, Geneva, Switzerland.

Published: 20 June 2013

doi:10.1186/2047-2994-2-S1-P125

Cite this article as: Joubert et al.: P125: Promoting hand hygiene in intensive care: a permanent challenge. Antimicrobial Resistance and Infection Control 2013 2(Suppl 1):P125.

Infection Control Program, University of Geneva Hospital, Geneva,

Switzerland

Full list of author information is available at the end of the article

(c) 2013 Joubert et al; licensee BioMed Central Ltd. This is an Open Access article distributed under the terms of the Creative Commons 